\title{
BREATHING THE UNIQUENESS OF KUNKANA CULTURE BY \\ WORD-OF-THE MOUTH TRADITION
}

\section{MEERA VASANI}

Department of Humanities Institute of Infrastructure Technology Research and Management (IITRAM),

Ahmedabad, Gujarat, India

\begin{abstract}
To safeguard many such endangered Indian aboriginal languages; Central Institute of Indian Languages in collection with the Bhasha Research and Publication Center, founded by Shre Ganesh Devi has published the original as well the translation of The Ramayan and other Oral Narratives of the Kunknas and many other like works with a spirit to empower the smaller mother tongues.
\end{abstract}

Kunkana community comes from the Dang district of Gujarat, which is considered the extreme end of the western side of the tribal belt of our country and they speak Kunkna and Warli language, which is frequently overlapping and mutually interchangeable. The word Kunkna has been derived from the Persian word canarim, meaning seashore.

Kunkana is a distinct language. Similarly, its oral tradition is very special. The people of the community celebrate several festivals and their oral literature is associated with these festivals and occasions. This community has several narratives which sometimes dates back in the $19^{\text {th }}$ century and sometimes to the $16^{\text {th }}$ century and take entirely the whole night when perform.

This paper was an attempt to study the Kunka version of the Ramayan, which is not an indigenous story but it is he imported and mixed stories of the imagination of the performer.

KEYWORDS: Kunka Community, Kunkana Language, Oral Literature, Ramayan, Festivals \& Rituals

Received: Jul 31, 2018; Accepted: Aug 21, 2018; Published: Aug 31, 2018; Paper Id.: IJELOCT20183

\section{INTRODUCTION}

Traditionally India has viewed as a pluralistic society that is an amalgamation of many languages. But in the rat-race of development, many of the languages are losing its importance and its place in keeping up its identity. According to the recent UNESCO report, in India, we have all kinds of language situations ranging from potentially endangered to those on the verge of extinction.

Language dies with cultural erosion is a fact of the human existence: Ten languages die out each year. International action is needed to counter this erosion of cultural diversity.

The word Konkan and, in turn, Konkani, is derived from Kunkan or Kunkani. Different authorities explain the etymology of this word differently. Some include:

- Kon meaning top of the mountain. 
- Name of the aboriginal mother goddess, which is named as Renuka.

Thus the name Konkane, comes from the word Konkan, which means the people of Konkan.

The Aryans who migrated to India familiarized themselves in North India and established several languages based on the local influence. Depending on their geographical dispersion you can categorize two distinct groups: Punjabi, Rajasthani, Gujarati, and Hindi evolved from Prakrit of Magadha and Sindhi Maithili, Assamese, Bengali originated from Shouraseni Prakrit. Konkani belongs to the second group, and hence some scholar regards Bengali or Assamese as the mother of Konkani language. However, in reality, the three are siblings of the same now non-existent intermediary parents' language. The arguments on the matter continue to generate a lot of response among linguist. Some historians argue that it was the language of Aryans who came further south to the Konkan, and hence the name Konkani. The most important point to note here is that Konkani is first seen in the konkan area. Early adopters used the Brahmi script, but eventually, due to the local influence, Nagari (a. k. a. Devanagari) was used for the benefit of a much larger audience.

Thus Konkani people (Konkani look also Konkane, Konkastha) who are an ethnolinguistic community found mainly in the Konkan Coast of southwestern India whose mother tongue is the Konkani language. The Konkani people speak different dialects of Konkani, their native tongue; although very high percentages are bilingual.

\section{KUNKANA RAMAYAN}

The great epic Ramayan as written and understood by any common people and the Kunna version of Ramayan and Ram is totally different. To the Kunkna community in Dang, it is not a piece of literature but a social document. When people did not have the modern means of entertainment available to them, they used to gather at the nukaad or choraha and listened to the public recitations of the stories. This can be compared to the stores of how plays came into existence in the history of English Literature in the pre-Elizabethan era. The story-teller is known as Bhagat. He narrated and enacted the incidents to make it lively. This appealed highly to the emotions of the audience. These tellers held a high place in the society. These bhagats of Dang regions worship Ram, Sita and especially Hanuman. In this oral literature Ram. Sita, Ravan, Lakshman etc. are shown as ordinary human beings but Hanuman has some extraordinary qualities. Their Gods in the shrine have different qualities than their gods of oral literature. While performing these stories the main instrument the bhagat uses a large dish made up of metal, he recites and plays on it like a table and sings. His chorus will recite the refrain and enriches the impact of the action. The popular refrain used by them is.....jigana ji...ji...ji these bhagats perform religious rituals and ceremonies, as well as recite the tales meant for these occasions. All these literary traditions is preserved orally by the community.

Prior the main story begins he invokes goddess Sarasvati the first. The Mahadev \& Parvati, then he bows to Goddess Amba and Goddess Saptashringi. Fourthly he prays to Kansari (Goddess of fertility), Mavli and Goddess Himai. Along with the list of other gods and goddesses, he also pays tribute to the sacred places like Suryagadh, Buraygadh, Gadhagabari, Shukla Tirtha, Surita Gadha, Belakapar etc. Along with these he also bows to the Pole star, to the people of his village, to the village itself, to the divine earth, the age of Kali and the God of death. After all the deities, he also pays homage to the ghosts, witches, and spirits. Make a horse of a pestle, tails of a broom, cross twelve roads and twelve crossroads. He also seeks pardon for the mistakes that he is likely to commit while the recitation.

The Kunkna version of the Ramayan is not an indigenous story; on the contrary, it is imported from other regions of India. The performer of the Kunkna story re- imagines it in the settings familiar to the Kunkna people and thus satisfies 
listeners who recognize the customs and locales mentioned by the narrator. Consequently, people associate many sites and monuments of their region with the incidents of the stories and are proud of believing that the characters of the stories had actually visited those places or they belonged to those place only. Like Mahadev belonged to Dhavalegir, Ravan was from Opingpur and eventually, he became the king of Lanka.

\section{HUMAN CHARACTERS}

Gods of the oral narrative are given the human attributes like love, jealousy, excited, stealing, kidnapping, playing tricks etc. to give liveliness to the narrative. Even the dressings are that of a common Bhil.

Narandev took off hid extravagant clothes and put on the simple clothes of a Bhil - a loincloth, a head dress and a coarse, sleeveless vest.

(The Ramayan; 7)

Gods are given the occupation of the community like cattle rearing, tilling the lands, harvesting crops etc. To even represent the story more realistically not only the setting costumes, occupation is theirs but even the remedies suggested are also making their culture breath. King Jambu is the character from Kunkna Ramayan, his kingdom was facing drought one night he dreamt that his gardens and his people had become fertile. He woke up and told his wife about the strange dream. He wanted to visit his gardens and check but his queen was annoyed by his childish talk. So she insisted: Go to sleep and enjoy your dreams and let me sleep too. However, Jambu was determined to visit the gardens. So to cure him of his madness she asked him to wait for some time and: The queen heated the blade of a plough and seared his buttocks with $i t$. This is a general belief among the community that when a person talks of some impossibility then he is considered mad and given the same treatment.

Ram in Kunkna Ramayan is a common human being, not an incarnation. The heroic quality of the traditional Ram is not found in this Ramayan. Even the Swayamvar of Sita was not worn by Ram but

Lakshman. When Sita came blushing forward with the aarati to worship him he said,

I am not of royal lineage and so you should not marry me. Besides, I participated in the competition with the consent of my brother, Ram. Hence, you should marry him.

(The Ramayan; 60)

In the forest when Ram went following Ravan disguised as the peacock, Sita insisted Lakshman to go in search of Ram on denying she is found blaming Lakshman as:

I wonder why you want to be near me in Ram's absence. If this is what you wanted you should have accepted me as your wife at the wedding contest.

(The Ramayan; 66)

Such features in Sita's character make her appear as a common human living in and around. Eventually, when Sita was kidnapped and Ram came at the hut and found Lakshman's wooden slippers lying outside his room. He thought: Does it mean that Sita is also inside the room? And Lakshman....? (The Ramayan; 69) Such and many other instances are narrated with a human touch. 


\section{SOUL JOURNEY}

About the soul's journey, this community has its own belief, which is narrated in the oral literature very clearly. When Dashrath's first wife dies Kal and Vel came close to Gorilakshmi's bed. Kal clamped his pincers which he used to draw out the soul of a person, on her foot. Her soul jumped to her knee. Kal placed the pincers on her thigh and immediately the soul skipped to her heart. The moment this happened, Gorlakshmi found it difficult to breathe. She started tossing around in her bed. Kal, determined to complete his task, touched Gorilakshmi's heart with the pincers. Gorilakshmi's soul leaped to her throat, and then from her throat, it went to her head. At last, when Kal put his pincers on Gorilakshmi's head, her soul was caught. Vel put the soul in the cage. Then Kal and Vel left. Thus, it shows that the community believes that Kal and Vel come to take back the soul in a cage.

\section{ANIMAL IMAGERY}

Animal imagery plays a vital role in the oral literature. Cow, bullock, birds, squirrel, owl, crow, bulbul etc. are found talking, pleading, and arguing. In the narrative when Sita was forcefully taken to Lanka by Ravan, she pleaded to bulbul, female dove, and squirrel to inform Ram that she was abducted by Ravan. They all agreed and she blessed them with various gifts like; vermilion to bulbul, strokes to squirrel etc. Moving ahead when she saw a chameleon and requested it to pass the message to Ram he denied so she cursed him saying,

You are so arrogant! I curse you so that your body will change colors during the monsoon and whenever children see you they will stone you to death....

(The Ramayan; 68)

\section{OTHER STORIES}

At the time of harvest, the Tale of Kansari is recited, Kansari is the goddess of food for the Kunkna community. A sprout is called Kasa in Sanskrit. The tale of Kansari deals with the themes of creation, doom, re -creation, and the history of human ancestors and the heroes of humankind. This is the story of the origin of the earth. Every tribal community has its own tale of the origin of the earth and human society which is recited through their oral literature and is transmitted from generation to generation. This story can be compared and contrasted with the Bible story of Noah's Arch. And with the story of the origin of the Canadian native community Metis' named Foods \& Spirit, where turtle origin story comes in picture.

During the festivals of Navratri, The Tale of Mavli is sung. Before the tale of Dungardev, the god within the cave of the mountain is recited. All this community believe in nature as God and natural things as the incarnation.

The recurrent imagery of fetching the water either with a golden pitcher, a silver pitcher, and a leather pitcher is found. These may indicate that this community may be facing the water crisis. Other images of Mahadev, Dwarka Devalgiri etc. appear as if these people believe that Gods reside there. Image of Gourd is common in almost all the tales, as it is used by this community as food as wells as it can be shaped and used as utensils.

The importance of women is clearly visible in this narration. Women are shown doing all the household chores. Be it a queen, a goddess, a common general woman is shown going to fetch water, preparing food, following all the rituals of body and matrimonial. Importance of women voice in the decision is shown in the married life of Dashrath and Kaykauchala. Woman's valor is surely found in almost all the narration. 
Every day is like a festival in the life of the Kunkna Community. At some place or the other, the recitation of tales goes on almost daily. These tales are narrated to the accompaniment of thali. Dera is another instrument which is used by this community to make it more appealing. A mataki is put into a basket and some leaves of teak are tied around the neck of the mataki. To these leaves are tied the feathers of a peacock. When the feathers are rubbed they create a very sweet time. Such oral literature breather this community's uniqueness.

\section{CONCLUSIONS}

Thus, through these stories the community tries to sustain their originality. The stories are narrated orally to the gathering and it is left on the discretion of the audience. The cultural representation of these stories is visible in the life style of the community. The beliefs, the rituals, the traditions are now vanishing slowly from the clan due to variety of reasons, yet the efforts of Shri Dahyabhai Vadhu and Mr. Bhagwanbhai Patel to prepare the documents so as to keep their identity thriving is commendable.

\section{REFERENCES}

1. The Ramayan And other Narratives of the Kunkna; Dahyabhai Vadhu, translated by Avaneesh Bhatt; Central Institute of Indian Languages and Bhasha Research \& Publication Centre.

2. https://sites.google.com>site > unesco.report 
